\title{
MAKNA DAN FUNGSI MAGIS
}

\section{SYAIR ACAPELLA PADA RITUAL PEMANDIAN SENJATA \\ TRADISIONAL MASYARAKAT KEC. KEDUNGDUNG}

\author{
Ika Agustiningsih; Ni Made Emi N; Romadloniyah N.T \\ Pendidikan Bahasa dan Sastra Indonesia \\ Universitas Muhammadiyah Malang \\ ikaagustin747@gmail.com
}

\begin{abstract}
Abstrak
Penelitian mengenai makna dan fungsi magis pada ritual pemandian senjata tradisional masyarakat Kec. Kedungdung dilaksanakan setiap tanggal satu suro. Ritual pemandian senjata tradisional dilaksanakan untuk memperingati rokat dhisah atau yang disebut dengan selamatan desa. Masyarakat kedudung percaya bahwa dengan mengucapkan syair acapella akan menambah kesakralan terhadap upacara tersebut. Penelitian ini perlu dilakaukan lebih lanjut mengingat semakin pudarnya sastra lisan yang ada di Indonesia khususnya Madura akibat dari dampak kebudayaan asing yang masuk tanpa difilter. Penelitian ini bertujuan untuk melestarikan budaya masyarakat Madura dengan mencari makna dan fungsi magis terhadap syair acapella. Penelitian ini juga menggunakan metode hermenotika yaitu pencarian makna yang optimal pada syair acapella dan menggunakan jenis penelitian deskrptif kualitatif serta menggunakan pendekatan antropologi sastra. Sumber data yang digunakan yaitu syair acapella dan informant serta menggunakan teknik dokumentasi, perekaman, pengamatan, pencatatan, dan wawancara. Pengecekan keabsahan data dalam penelitian yaitu teknik triangulasi teori dan metode yang didapatkan dari buku dan jurnal.
\end{abstract}

\section{Kata-kata kunci: Syair Acapella, Makna, fungsi Magis, Senjata tradisional}

\begin{abstract}
Research on the meaning and function of magical ritual bathing of traditional weapon of society Kec. Kedungdung held every date one suro. Traditional weapon bathing rituals are held to commemorate the dhisah or so-called village rug. Society veil believe that by reciting acapella poem will add sanctity to the ceremony. This research needs to be done further considering the waning of the oral literature that exists in Indonesia especially Madura as a result of the impact of foreign culture that goes without being filtered. This study aims to preserve Madurese society by searching for magical meaning and function against acapella poetry. This research also uses hermenotika method that is searching for optimal meaning in acapella poetry and using descriptive qualitative research type and using literary anthropology approach. Sources of data used are acapella and informant poems and using documentation, recording, observation, recording, and interview techniques. Checking the validity of data in research is triangulation theory theory and methods obtained from books and journals.
\end{abstract}

Keywords: Acapella Acronym, Meaning, Magical function, Traditional Weapon 


\section{PENDAHULUAN}

Indonesia merupakan salah satu negara kepulauan yang mempunyai keanekargaman budaya. Berbagai budaya lahir dari daerah atau suku yang berbeda. Adanya perbedaan tersebut menjadikan budaya Indonesia tampak unik dan mempunyai ciri khas bawaan dari daerah masing-masing. Hal ini sejalan dengan pemikiran Koentjarani (dalam Soehardi, 2002:2) yang menyatakan bahwa nilai budaya daerah tentu saja bersifat partikulastik, artinya kekhasan berlaku umum dalam wilayah budaya suku bangsa tertentu. Sejak kecil individu-individu telah diresapi oleh nilai-nilai budaya masyarakatnya, sehingga konsepsikonsepsi itu telah menjadi berakar dalam mentalitas mereka dan sukar untuk digantikan oleh nilai budaya lain dalam waktu yang singkat.

Menurut (Nur' Aini, dkk 2013:2) bahwa kebudayaan tersebut seperti bahasa, kepercayaan, keyakinan, pakaian tradisional, tarian tardisoanal, senjata perang, kuliner serta upacara adat. pada dasarnya semua kebudayaan tersebut memiliki makna dari daerah tertentu yang dianggap sakral oleh masyrakatnya.

Madura merupakan salah satu pulau yang berada di negara Indonesia tepatnya sebelah timur pulau Jawa yang mempunyai anekaragam budaya. salah satu budaya yang ada di Madura tepatnya di Kabupaten
Sampang Kecamatan Kedungdung yaitu Upacara Ghumbak. Upacara ini digunakan sebagai sarana penyucian benda pusaka berpetuah dan sekaligus memperingati rokat dhisah atau selamatan desa.

Pelaksanaan upacara tentu saja tidak lepas dari berbagai ritual maupun doa atau mantra yang diucapkan oleh seseorang yang dipercayai sebagai petuah di daerah tersebut yang dilakukan sesuai dengan kepercayaan atau keyakinan masyarakat setempat untuk tetap melestariakn kebudayaan. Hal ini sejalan dengan pemikiran (Wardani, 2017:66) menyatakan bahwa ritual keagamaan biasanya mempunyai bentuk atau cara melestarikan serta maksud dan tujuan yang berbedabeda antara kelompok masyarakat yang satu dengan masyarakat yang lain.

Mantra atau doa merupakan bagian dari puisi lisan yang belum diketahui oleh banyak orang. Beberapa orang menganggap puisi yang dibacakan merupakan puisi lisan. Hal ini sangat berbanding terbalik dengan pengertian puisi. Puisi adalah bahasa perasaan, yang dapat memadukan suatu respon yang mendalam dalam beberapa kata. Puisi termasuk salah satu bentuk karya sastra. Kehadiran sebuah puisi merupakan pernyataan seorang penyair yang beirsi pengalaman batinnya sebagai hasil proses kreatif terhadap objek seni (Sulkifli, 2016:2; Amin., dkk, 2013:31) 
Keberadaan mantra atau doa di sekeliling masyarakat Indonesia sebenarnya sudah lama dan sangat erat kaitannya dengan kebudayaan maupun keyakinan yang dikenal dalam dunia sastra sebagai puisi lisan dan sangat erat kaitannya dengan persoalan makna karena mencakup segala aspek kehdupan manusia. Kedua hal tersebut merupakan bentuk yang diwariskan oleh nenek moyang terhadap generasi penerus secara turun temurun (Zekriady, 2008:295; Syamsurijal, 2014:251-252). Meskipun demikian tidak menutup kemungkinan bahwa sastra lisan banyak yang sudah hilang eksistensinya karena sudah tidak diyakini lagi oleh masyarakat atau tidak lagi disakralkan karena dianggap tidak mempunyai fungsi magis di dalamnya.

Pernyataan di atas sejalan dengan asumsi Teeuw (2013:252), bahwa sebagian besar sastra di Indonesia telah hilang dan tak berbekas. Sastra lisan yang masih ada saat ini atau yang masih bisa diselamtkan sejak abad yang lalu tentunya berkat usaha peneliti dalam melestarikan meskipun belum tentu membayangkan sastra lisan asli atau purba.

Masyarakat Madura merupakan salah satu contoh komunitas yang masih melestarikan sastra lisan sehingga dapat teraktulaisasikan sampai saat ini. Penerapan tersebut tampak ketika pembacaan doa atau mantra dalam pelaksanaan upacara Ghumbak. Sisi yang menarik dalam upacara Ghumbak yakni pada saat pengarakan 26 senjata tradisional yang diiringi dengan syair berbahasa Madura dalam bentuk acapella menuju makam bujuk Toban dan bujuk Bung Kenek yang aggap sebagai pencipta dari senjata tradisional tersebut.

Permasalahan dalam penelitian ini yaitu Bagaimana makna tekstual yang terkandung dalam syair Acapella yang digunakan sebagai lagu dalam mengarak 26 senjata tradisional Madura Khususnya masyarakat Kec. Kedungdung? Bagaimana fungsi magis dari lagu acapella sehingga dipercaya sebagai doa atau mantra yang sakral dikalangan masyarakat Madura Khususnya daerah Kec. Kedungdung?

Upacara Ghumbak khususnya pada mantra atau doa yang digunakan untuk pengarakan senjata tardisonal belum mendapatkan perhatian khusus dari masyarakat setempat karena kurangnya pemahaman masyarakat terhadap makna yang terkandung dalam doa atau mantra tersebut.sehingga dibutuhkan pengakjian lebih lanjut mengenai pencarian makna terhadap syair dalam bentuk Acepella yang dianggap sakral oleh masyarakat Madura.

Mengingat kedudukan dan peranan sastra lisan sangat penting, penelitian sastra lisan perlu dilakukan sesegera mungki. Lebih-lebih bila mengingat terjadinya perubahan dimasyrakat seperti kemajuan 
teknologi komunikasi. Penyelamatan dilakukan sebagai usaha dalam pewarisan nilai-nilai budaya, karena dalam sastra lisan ditemukan nilai moral, falsafah, ideology, dan kearifan suatu bangsa. Nilainilai tersebut bisa diwariskan kepada anak cucu kelak (Suantoko, 2017:42). Hal itu, mengingat hampir disetiap daerah di Indonesia mengenal sastra lisan begitu juga dengan masyarakat Madura Kec. Kedungdung

Penelitian ini menggunakan teori Roland Barthes bahwa terdapat dua sistem semiologi yang meliputi sistem denotasi atau makna literal dan sistem konotasi atau makna budaya. Pencarian makna yang terdalam serta memberikan sebuah pandangan terhadap masyrakat akan fungsi magis dari syair acapella semakin menguatkan bahwa kajian ini menggunakan teori tersebut.

Alasan menggunakan teori semiotika Roland Barthes karena selain dapat menjelaskan sitem tanda dan penanda atau disebut dengan signified dan signifier teori ini selain dapat sebagai penghubung yang sangat esensial dalam berkomunikasi. Teori semiotika Barthes dapat dipakai untuk menjelaskan mitologi. Menurut Barthes. Mitos ialah sebauh sistem komunikasi yang merupakn pesan dan tidak mungkin menjadi objek, konsep spesifik bahka ide. Mitos menurut orde kedua sebagai sistem semiologi yang berupa tanda (total asosiatif dari konsep gambar) hanya menjadi penanda belaka saja.

Menurut Barthes (dalam Putra, 2010: 229), tanda sebagai urutan pertama dari sebuah sistem atau bahasa, sebgai objek sementara mitos disebutnya sebagai metabahasa metalanguage. Dasar teori semiotika ini seluruhnya dari buku Barthes berjudul Mythologies (1972).

Menurut (Asrofah, 2014:4) pada dasarnya, ada perbedaan antara denotasi dan konotasi dalam pengertian secara umum serta denotasi dan konatasi yang dipahami oleh Bharthes. Dalam semiolgi Bhartes dan para pengikutnya, denotasi merupakan sistem signifikasi tingkat pertama sedangkan konatasi merupakan tingkat kedua. Dalam hal ini denotasi justru lebih diasosiasikan dengan ketertutupan makna.

Sistem denotosi dan konotasi sangat erat kaitannya dengan toeri fungsi yang terdapat didalam kandungan makna. Seperti yang dikatakan oleh William. R. Bascom yang menyatakan bahwa folkor mempunyai beberapa fungsi dalam kehidupan masyrakat salah satunya yaitu sebagai alat pemaksa norma dan pengawas norma-norma masyarakat dimaksudkan bahwa sastra lisan berisikan petuah-petuah, etika, dan norma-norma yang perlu diikuti atau dipatuhi oleh masyarakat. Hal ini 
sangat berkaitan dengan fungsi dari syair Acapella tersebut.

\section{KAJIAN PUSTAKA}

Roland Barthes (dalam Ratna, 2015:260) proses pemaknaan tidak terbatas pada bahasa akan tetapi dapat juga meliputi seluruh kehidupan namun tetap atas dasar konsep-konsep linguistik, sebagaimana dilakukannya dalam analisis berbagai gejala masyarakat dalam bukunya yang berjudul "Mythologies"berkaitan dengan teks dan tidak memebedakan antara teks sastra filsafat dan agama.

Asumsi dasar teori Roland Barthes adalah munculnya makna yang misterius di balik sebuah mitos (Asrofah, 2014:5). Barthes memberikan perbedaan terhadap makna denotasi dan konotasi. Denotasi adalah sistem signifikansi tingkat pertama sementara konotasi merupakan tingkat kedua. Denotasi lebih bersifat operesif atau yang disebut dengan ketertutupan makna. oleh karena itu Bhartes berfokus pada satu makna saja yaitu Konotasi yang identik dengan mitos dan berfungsi untuk mengungkapkan dan memberikan pembenaran bagi nilai-nilai dominan yang berlaku dalam suatu peroide tertentu.

Asumsi dasar dari teori William R. Bascom dalam (Widianti, dkk. 2017:117 ) mengungkapkan empat fungsi foklor, anatara lain (a) sebagai sistem proyeksi, yakni alat pencerminan angan-angan suatu kolektif; (b) sebagai alat penegesahan pranata-pranata dan lembaga-lembaga kebudayaan; (c) sebagai alat pendidikan anak: (d) dan sebagai alat pemaksa serta pengawas agar norma-norma masyarakat akan selalu dipatuhi anggota kolektifnya.

Barthes juga mengatakan bahwa mitos sebagai sistem bahasa selalu sudah mengandung ideologi. Konsep pada sistem mitos merupakan ide-ide atau gagasan kelompok tertentu yang menyelewengkan sistem bahasa dalam sistem mitos tadi demi kepentingan kode yang ada dalam kelompok tersebut. artinya, gagasan tidak berangkat dari ruang kosong. Ia muncul karena ada persoalan yang mesti diatasi olehnya. Akan tetapi, untuk mendapatkan legitimasi mesti menggunakan sistem bahasa yang ada. Mitos yang sudah sedemikian mapan menjelma menjadi idiologi (Mubarok, 2007)

Teori fungsi Willam R. Bascom jika dikaitkan dengan objek penelitian, yaitu fungsi magis syair acapella, maka dapat paparkan sebagai berikut: (a) sebagai sistem proyeksi yang menunjukkan mengenai pandangan, pemikiran, dan visi masyarakat pemilik sastra tersebut.(b) sebagai alat penegesahan pranata dan lembaga kebudayaan yang akan memepresentasikan dan membenarkan keberadaan pranata dan lembaga kebudayaan serta (c) sebagai alat pemaksa norma dan pengawas norma-norma masrakat dimaksudkan bahwa sastra lisan berisikan petuah-petuah, etika, dan norma- 
norma yang perlu diikuti atau dipatuhi oleh masyarakat.

Teori fungsi dan makna dalam sangat tepat digunakan dalam kajian ini karena akan membantu dalam menjelaskan masalah penelitian mengenai pencarian makna konotasi dalam syair acapella dan fungsi magis dari syair tersebut. terbutkti tanpa adanya syair tersebut dalam upacara pemandian senjata tradisional maka akan mengurangi kesakralan acara tersebut.

\section{METODE}

Penelitian ini menggunakan metode hermeneutika. Secara etimologis, istilah hermneutik berasal dari Bahasa Yunani hermeneuein yang memiliki arti 'menafsirkan' (Ashadi, 2017:3). Hermneutik secara umum didefinisikan sebagai ilmu filsafat tentang penafsiran atau interpretasi makna dan mengacu pada makna yang optimal.

Jenis penelitian yang digunakan yaitu deskriptif kualitatif karena menggunakan Syair "acapella sebagai objek kajian. Arikunto (2010:3) mengatakan bahwa penelitian deskriptif kualitatif adalah penelitian yang dimaksudkan untuk menyelidik keadaan, kondisi, atau hal-hal lain yang sudah disebutkan, yang hasilnya dipaparkan dalam bentuk laporan penelitian.

Penelitian ini menggunakan pendekatan antropologi sastra. Menurut (Ratna 2011:31) antropologi sastra merupakan analisis dan pemahaman terdapat karya sastra dalam kaitannya dengan budaya. Antropologi pada dasarnya merupakan penelitian yang dilakukan oleh kelompok orientalis, penelitian untuk bangsa-bangsa timur, untuk mengetahui lebih jauh tingkat kehidupan dan peradaban bangsa tersebut secara keseluruhan.

Sumber data yang digunakan ialah syair acapella dan informant. Hal ini disebabkan oleh adanya pencarian makna secara mendalam dan fungsi magis mengenai sayir aceplla tersebut. menjaring data yang dibutuhkan, mencari informasi tentang kondisi gografis, kondisi sosial budaya masyraakt setempat atau di daerah penelitian. Data yang digunakan adalah mantra yang diucapakan berupa syair acapella.

Instrumen penelitian yang digunakan yaitu penelitian sendiri dengan menggunakan instrumen pemandu observasi, wawancara, dokumentasi. Teknik pengumpulan data yang digunakan dalam penenlitian ini yaitu studi dokumen dan wawanacara terhadap informant. Teknik studi dokumen dilakukan untuk mengumpulkan data maupun memperoleh informasi mengenai mantra syair acapella dengan cara membaca maupun mencermati mantar yang diproleh dari informant, sedangkan teknik wawancara dilakukan untuk mendapatkan informasi dari informant mengenai makna, serat fungsi 
magis dari syair acapella terhadap pemandian senjata tradisional masyarakat Kec. Kedungdung.

Teknik analisis data dalam penelitian syair capella yaitu teknik deskriptif. Teknik deskriptif dilakukan untuk memberikan gambaran mengenai keadaan atau status fenomena terhadap pembaca.

Pengecekan keabsahan data dalam penelitian ini menggunakan teknik triangulasi teori dan metode yang didapatkan melalui buku dan jurnal. Serta melakukan diskusi dengan teman sejawat maupun para ahli.

\section{HASIL DAN PEMBAHASAN}

Semiotik merupakan sistem pencarian makna yang terdapat dalam pemaknaan konotasi yang dianggap mempunyai ambiguitas dalam pemaknaannya. Seperti yang dikatakan oleh Sausure (Sobur dalam Sulistyorini dan Andalas, 2017: 41) menjelaskan bahwa tanda disusun dari dua elemen, yaitu: aspek citraan tentang bunyi (semacam kata atau reperesantasi visual) dan sebuah konsep dimana citra bunyi disandarkan.

Seperti halnya yang dikatakan oleh peneliti bahwa mantra Acapella mempunyai banyak makna konotasi di dalamnya mulai dari doa sampai dengan gerakan yang dilakukan dalam menyakralkan atau penyucian benda tardisonal. Terdapat beberapa tahap dalam mengarak 26 senjata tardisional yaitu tahap baceman atau yang disebut dengan tahap pembasuhan senjata tradisional dalam air kembang yang disertai dengan pembakaran kemenyan yang dipimpin oleh pemangku adat setempat.

Sebelum dilaksanakannya upacara Ghumbak diadakan selamatan tajin atau bubur putih. Hal tersebut dimaksudkan dengan tujuan untuk mengharapkan ridha Allah agar acara ini selamat tuntas dari awal sampai akhir. Acara ini akan dilalui oleh beberapa tahapan yaitu tahap pertama dan tahap kedua yang nantinya kita akan ikuti bersama.

\section{Do'a pada pembaceman pada senjata tardisional}

Walau anna Quranna

Suyyirot bihil jibelu

Aukiti' at bihil ardhu aw kullima bihil mauta Ballillahil amru jami'a.

Innahu min Sulaimana

Wainnahu bismillahirrohmanirohim

Ala' ta'lu alayya waktuni muslimin

Minta' sakulillana kerreseh umpingngah

Nabi sulaiman

lailahaillahmuhamadarrasullah

Negerengah sengkok ngassanah keres

Dalam bait pertama sampai dengan ke emapat doa pembaceman pada senjata tradisional di ambil dari ayat alqur'an Surah- Ar-Rad ayat 3. "dan sekiranya ada suatu bacaan (kitab suci) yang dengan bacaan itu gunung-gunung dapat digoncangkan atau bumi jadi terbelah atau oleh karenanya orang-orang yang sudah mati dapat berbicara, (tentulah al-qur'an itulah dia. Sebenarnya segala urusan itu 
adalah kepunyaan Allah. Maka tidaklah orang-orang yang beriman itu mengetahui bahwa seandainya Allah menghendaki (semua manusia beriman), tentu Allah memberi petunjuk kepada manusia semuanya.

Sebenarnya dalam ayat tersebut mempuyai makna doa pengasih terhadap seseorang yang diidamkan, namun pada konteks ini ayat tersebut bermakna untuk menarik perhatian masyarakat dan lebih afdhol apabila dibaca sebanyak tujuh kali. Ayat tersebut juga digunakan karena tidak ada niatan untuk menduakan Allah namun semata-mata untuk menjaga kesakralan dan kelestraian kebudayaan dari senjata tradisional tersebut.

Digunakannya ayat di atas dalam pembaceman senjata tradisional berfungsi agar senantiasa mendapatkan ridha Allah serta mendapatkan perhatian dari masyrakat setempat untuk selalu melestarikan upacara adat pemandian senjata tradisional sehingga tak lekang oleh waktu.

Hal ini sejalan dengan pemikiran (Ratna, 2011:125) yang menyatakan bahwa karya sastra merupakan sebuah refleksi dan rekonstruksi, sekaligus 'tiruan' hasil kebudayaan pada masa tertentu. Karya sastra adalah strategi agar dapat melengkapi kebutuhan manusia, baik bagi segi emosional maupun intelektual, strategi-strategi yang tidak mudah dilakukan oleh ilmu pengetahuan lain. seperti dengan konteks di atas, melalui karya sastralah kebudayaan suatu bangsa dapat dijadikan identitas bangsa secara keseluruhan dikenal oleh negara lain.

Pada bait kelima sampai dengan bait ke delapan di ambil dari ayat alqur'an Surah An-Naml ayat 30-31. Sesunguhnya surat itu, dari sulaiman dan sesungguhnya (isi)Nya: dengan menyebut nama Allah yang maha pemurah lagi maha penyayang. Bahwa janganlah kamu sekalian berlaku sombong terhadap $\mathrm{ku}$ dan datanglah kepada ku sebagai orang-orang yang berserah diri”.

Digunakannya ayat ke 30-31 Surah An-Naml atas perintah Nabi Sulaiman agar dalam segala urusan hendaknya selalu melibatkan Allah terutama pada acara sakral seperti pembaceman senjata tradisional. Agar menciptakan sifat rendah diri terhadap sesama khususnya masyarakat Madura Kec. Kedungdung dalam meyakini bahwa acara tersebut juga di dampingi oleh Nabi Sulaiman.

Doa pembasuhan pada senjata tradisonal dengan menggunakan air kembang dipercayai sebagai sarana penyucian senjata tradisional tersebut agar terhindar dari hal-hal yang negatif. Tradisi tersebut juga diiringi oleh membakar kemenyan yang dipimpin oleh pemangkau adat setempat yang dipercayai sebagai 
petuah masyarakat Madura kecamatan Kedungdung.

Pada bait ke Sembilan sampai dengan sebelas masyarakat Kedungdung meminta keikhlasan dari senjata tersebut agar senjata tersebut berkenan untuk dibasuh sehingga terhidar dari ha-hal yang negatif dengan tetap meminta dampingan dari nabi Sulaiman dalam pembasuh senjata Tardisoinal Madura.

\section{Tahap kedua pemandian senjata tradisional}

Sebelum ritual pemandian senjata tradisional dimulai masyarakat yang mengikuti upacara tersebut berputar sebanyak tujuh kali dengan memegang senjata yang akan di arak menuju tempat pengarakan satu senjata hanya bisa dipegang oleh satu orang. Masyarakat Madura khususnya kecamatan Kedungdung mengibaratkan peristiwa tersebut seperti thowaf.

\begin{tabular}{|l|l|}
\hline \multicolumn{1}{|c|}{ Syair } & \multicolumn{1}{|c|}{ Arti } \\
\hline He le le le le le & He le le le le le \\
Sabe bendung & Sawah lapang \\
Namen magik tombu & $\begin{array}{l}\text { Menanam biji tumbuh } \\
\text { sukun }\end{array}$ \\
sokon & Rumah bambu banyak \\
kalanah kerep benyak & kalajengkingnya \\
Oreng odik kodhu & $\begin{array}{l}\text { Orang hidup harus } \\
\text { rukun agar bagus } \\
\text { rokon pola } \\
\text { Makle begus } \\
\text { tengkanah" lakunya }\end{array}$ \\
\hline
\end{tabular}

Syair tersebut memberikan makna masyarakat Madura masih meyakini bahwa dengan adanya pemandian senjata yang diarak bersama oleh masyarakat Kec. Kedungdung akan menambah sikap rukun antar sesama. Tingkah laku yang baik merupakan tingkah laku yang diharapkan oleh semua orang khususnya masyarakat Madura yang masih menjunjung tinggi kekeluargaan. Sejalan dengan pemikiran (Musdalifah, 2016:11) yang menyatakan bahwa kebaikan dan kedamaian merupakan suatu bentuk dari nilai kerukunan. Kedua bagian tersebut sulit dibedakan, karena di dalamnya terkandung nilai kerukanan yang terdapat pada pertalian persahabatan.

Perihal hidup rukun adalah adanya kebaikan dan kedamaian di dalam kesepakatan antarindividu maupun orang lain. Hal tersbut sependapat dengan Kaplan dan Maners (dalam Sulityorini dan Andalas, 2017:50) juga menegaskan bahwa dalam teori fungsi sebagai penyampaian ketergantungan antarsesama. Fungsi tersbut berupa fenomena budaya dan konsekuensi yang timbul dari tindak budaya atau proses kebudayaan fungsifungsi tersebut salah satunya yaitu fungsi sosial. Oleh karena itu syair /Namen magik tombu sokon/ tabeng kerrep benyak kalanah/ oreng odhik kodhu rokon/ makle bagus pola tengkanah/ mengandung makna selama hidup harus berperilaku baik agar menjaga kerukunan dengan warga yang lain sehingga menimbulkan tingkah laku yang baik pula. 
Fungsi yang terdapat dalam syair tersebut yaitu sebagai alat pemersatu masyrakat. Hal ini sejalan dengan pemikiran pemikiran William. R. Bascom (Widianti, dkk. 2017:117 ) bahwa sastra lisan berisikan menegnai petuah-petuah, etika, dan norma-norma yang perlu diikuti atau dipatuhi oleh masyarakat setempat.

\begin{tabular}{|l|l|}
\hline Syair & Arti \\
\hline Orambak orambe & Orambak orambe \\
Ngakan topak jukok & Makan ketupat ikan sate \\
sate & Keris sudah dimandiin \\
La akembeng la akem- & kembang sudah di \\
kem & rendam \\
Laepanggeng kerresse & Sudah dibakar kerisnya \\
laebecem & Sudah memenuhi syarat \\
Orambak ojeggur & pemandian \\
Nasi obi sella lorkong & Orambak orambe \\
& Nasi ubi campur ketela \\
\hline
\end{tabular}

Syair di atas mempunyai makna bahwa sesajen yang di berikan pada senjata tradisional tersebut berupa ketupat, dan lauk sate /ngakan topak jhukok sate/. Menurut Koentharani dalam skripsinya Hikmah yang berjudul Prosesi dan makna simbolis topen dan sesaji dalam kesenian Cepetan di Dusun Condong Desa Condong Capur Kec. Serueng Kabupaten Kebumen tahun (2014:25) sesaji atau sesajen adalah salah satu sarana upacara yang dtidak bisa ditingglakn, yang dihaturkan pada saat tertentu dalam kepercyaan terhadap makhluk halus di tempat tertentu pula atau yang disebut dengan mitos.

Hal tersebut juga sejalan dengan pemikiran Bhartes dalam (Sudewa, 2014:67) yang menyatakan bahawa mitos merupakan sistem komunikasi yang didalamnya ada pesan yang disampaikan. Pesan inilah yang menjadi keyakinan kehidupan religius magis sustau masyarakt. Misalnya sebgaian besar masyrakat Madura meyakini kebenaran sebuah mitos karena mitos kadang-kadan dapat memecahkan berbagai persoalan manusia yang tidak bisa diselsaikan dengan logika.

Senjata tardisional diarak setelah pembaceman dengan air kembang /la akembeng la akem-kem/ artinya syarat untuk pembaceman sudah terlaksana sebelum pada tahap pengarakan. /la e panggeng la ebecem/ senjata yang dalam perjalanan di arak sambil di asap-asapkan pada kemenyan yang sudah disediakan oleh masyarakat setempat sebagai sesajen. Selain ketupat dan sate masyrakat juga menyediakan umbi-umbian sebagai sesajen hasil dari panen /Nasi obi sella lorkong/. Syair di atas di ucapkan saat mengarak keris melwati sawah unutk mencari sumur tantoh atau sumur yang tidak pernah kering meskipun musim kemarau.

\section{Tahap pencarian sumur tantoh}

\begin{tabular}{|l|l|}
\hline Syair & Arti \\
\hline Dul janna Dul jennung & Dul janna Dul jennung \\
Tak andik anak abujel & Tidak punya anak, \\
kennong & anaknya orang lain \\
Tottolitottot nabuk & Tottolitottot mencabut \\
tenggeng & ketela pohon di sawah \\
kamengkangah & Buruh tani sakit lutut \\
Oreng ngoli sakek toot & karena pekerjaanya \\
Tak mendeng ka & namun tetap \\
otangngah & penghasilannya tidak \\
\hline
\end{tabular}


Orambak oradding

Olle aparak tak ole nyidding

Oladding o lattong

Tak olle esedding olle etongtong memadai untuk bayar

hutang

Orambak oradding

Boleh mendekat tidak

boleh menyentuk keris

Oladding olattong

Tidak boleh disentuh

kerisnya hanya bisa

dipegang gagangnya

Syair di atas menjelaskan bahwa dalam pemandian senjata tradisional tersebut dilaksankan oleh garis keturunannya /Dul janna dul jannng/ /tak andik anak abujel kennong/ bait tersebut menyatakan bahwa hanya anak keturunannya yang bisa membawa senjata tersebut mengelilingi desa. Menurut (Ratna, 2011:162) tokoh atau para pelaku dalam kebudayaan adalah orang dalam masyrakat, orang-orang dengan mekanisme antarhubungan bermakna, artinya, memliki tujuan tertentu. Tujuan yang dimaksudkan bukan semta-mata atas dasar kemauannya sendiri, melainkan dikondisikan oleh masyrakat dimana mereka berada. Mengelillingi desa pada pengarakan senjata tradisional bertujuan untuk memberitahukan pada masyarakat bahwa senjata tardisionah harus dilestarikan.

Pada saat inilah pengarak menyampaikan keluh kesahnya dalam menjalankan serangkaian penyakralakan senjata tradisional tersebut yang disampaikan dalam bait /Oreng ngoli sakek toot/ tak mendeng ka otangngah/

oleh karena itu setelah selesai dilakukan pembaceman dan pengasapan pada senjata tradisional tersebut tidak boleh ada satu orangpun yang menyentuh senjata tersebut namun hanya diperkenankan melihat dan memgang gagangnya saja /Olle aparak tak ole nyidding/ dan /Oladding o lattong Tak olle esedding olle etongtong/.

Syair tersebut juga berfungsi sebagai media masyrakat Kec. Kedungdung untuk menyampaikan keluh kesahnya selama menjadi buruh tani. Sehingga masyarakat yang lain (non petani) juga dapat merasakan hal yang sama.

\begin{tabular}{|l|l|}
\hline Syair & Arti \\
\hline Orambak orambe & Orambak orambe \\
Nase' obih selle lorkong & Nasi ubi campur ketela \\
Ananggele jek & Membajak sawah \\
pabendung & jangan sampai lapang. \\
Mon bendung nanggele & Jika lapang bajak \\
pole & kembali. \\
Asomajeh jek pa burung & Jika berjanji jangan \\
Mon burung asomaje & sampai ingakar \\
pole & jika ingkar maka \\
& berjanji lagi \\
& \\
\hline
\end{tabular}

Syair di atas bermakna menjelaskan kembali sesejan yang diberikan saat upacara Ghumbak yaitu /nase' obih sella lorkong/ makanan khas Madura yang dihasilkan dari hassil panen. Sedangkan pada bait ke tiga dan keempat mengandung makna orang yeng mempunya swah hendaknya selalu memanfaatkannya dengan baik supaya dapat menikmatai hasil panennya tersbut 
/Ananggele jek pa bendung /Mon bendung naggele pole/ sedangkan bait kelima sampai dengan keenam menyatakan bahwa pemandian senjata tradisional ini harus dilaksanakan tepat waktu setiap tahunnya.

Apabila pelaksanaan tersebut tidak dilaksanakan maka wajib untuk melaksanakan di tahun berikutnya lagi sperti yang syair yang berbunyi /asomaje jek pa burung/ mon burung asomaje pole/. Pada tahap ini juga dilaksanakan pelepasan ayam bagi orang yang mempunyai Nazar atau hajat. Ayam tersbut dapat ditangkap oleh siapun tanpa terkcuali sebagai keperacyaan bahwa hajatnya akan terkabulkan.

\section{Doa setelah selesai mengarak}

Seusai pengarakan terdapat sebuah doa yang mengandung permintaan agar tercapainya suatu tujuan. Selain itu doa tersebut diyakini agar ritual penyucian senjata tradisional selalu memberikan nilai yang positif bagi masyarakat setempat. Serta sebagai selmatan desa yang biasanya hanya dilaksanakan pada tanggal satu suro.

\begin{tabular}{|l|l|}
\hline \multicolumn{1}{|c|}{ Syair } & \multicolumn{1}{c|}{ Arti } \\
\hline Orambak orambe & Orambak orambe \\
Dek supandi bengla \\
bengku & Dikhususkan untuk \\
Bingta bingku, pancong & mbah Supandi \\
besse & berlapis bingku, keris yang \\
Minta sakulilanah be'na & Minta keikhlasannya. \\
kerres & Jika benar keris ini \\
Empu blambangan & empu blambangan \\
egelleh mancong & buatan dari kerajaan \\
Mon lakar gebeyyeh & majapahit maka keris \\
mojo pahit & ini akan mempunyai \\
Enggeleh manjeng & dzat \\
\hline
\end{tabular}

Syair di atas merupakan syair penutup dari uapaca Ghumbak. Syair tersebut mengandung makna bahwasannya senjata yang sudah dimandikan akan mempunyai dzat atau kepabilitas tersendiri yang diyakini oleh masyrakat Madura. serta doa yang dipanjatkan untuk mbah supandi yang dipercaya memberikan dzat atau kapabilitas pada senjata tradisional tersebut. Syair penutup hanya diucapkan oleh pemandu adat sebagai bentuk kesadaran masyrakt Kedungdung. Hal ini sependapat dengan pernyataan dari (Sulistyorini dan Andalas, 2017:49) Doa yang biasanya dipanjatkan oleh seorang Mudin dan Sesepuh merupakan bentuk bahasa sebagai ciri verbal dalam sebuah penelitian. Penuturan doa tersebut dapat menggunakan bahasa arab, bahasa Indonesia bahkan bahasa jawa sekalipun.

\section{Doa saat menghidangkan makanan} terhadap orong-orang selesai mengarak

\begin{tabular}{|l|l|}
\hline \multicolumn{1}{|c|}{ Syair } & \multicolumn{1}{c|}{ Arti } \\
\hline Daddhelli deddekung & Burung dadali dan \\
Nasek Obih sella & sebangsanya sebagai \\
lorkong & saksi \\
Le ollenah nasek & Nasi ubi campur ketela \\
burthong & Namun didapatnya nasi \\
& tumpeng \\
\hline
\end{tabular}

Syair tersebut diucapkan ketika menghidangkan makanan terhadap para pengarak senjata. Syair tersebut mengandung makna bahwa wajib adanya nasi tumpeng sebagai peringatan satu Suro. Selain itu juga dimaksudkan juga bertujuan untuk memperingati atau 
selametan desa bahkan burung dadali ikut serta dalam menyaksikan makan-makan yang dilakukan secara prasmanan.

\section{KESIMPULAN}

Syair Acapella merupakan Syair yang digunakan saat upcara Ghumbak atau yang disebut sebagi uapacara penyucian senjata tradisional. Syair tersebut dipercayai mengandung fugsi magis dalam pelakasanaan upacara Ghumbak. Tanpa adanya sayair tersebut dalam upacara Ghumbak dipercaya akan mengurangi kesakralan dari upacara tersebut. syair acapella dibacakan dalam beberapa tahap yaitu tahap pembaceman senjata tradisional dan tahap pengarakan senjata tradisional tersebut mengelilingi desa.

Syair acapella dipercaya oleh masyarakat Madura Kec. Kedungdung sebagai media pemersatu penduduk setempat, rokat dhisah atau yang disebut dengan selmatan desa dan sekaligus pelesatarian kebudayaan masyrakat Madura yang hampir punah karena tidak adanya kepedulian dan minimnya penerus yang terhadap tradisi yang ada.

Pembukaan upacara sakral tersebut diikuti oleh seluruh warga, yang dipimpin oleh tokoh ulama atau yang dipercaya sebagai petuah di desa Madura Kecamatan Kedungdung yakni melaksanakan dzikir dan doa-doa, dalam upacara ini diharapkan situasi dalam keaadaan hening, khidmad dan khusyuk agar memperoleh kelimpahan

Rahmad dan hidayah dari Allah SWT

\section{DAFTAR PUSTAKA}

Amin, Irzal, dkk. 2013. Cerita Rakyat Penamaan Desa di Kerinci: Kategori dan Fungsi Sosial Teks. Jurnal Bahasa, Sastra dan Pembelajaran. Vol. 1., No. 1:31

Arikunto, Suharsimi. 2010. Prosedur Penelitian. Jakarta: PT. Rineka Cipta.

Ashadi. 2017. Metode Hermeneutik Dalam Penelitian Sinkretisme Bentuk Arsitektur. Jakarta: Arsitektur UMJ Press: 3 .

Asrofah. 2014. Semiotik Mitos Roland Barthes Dalam Analisis Iklan Di Media Massa. Jurnal Sasindo. Vol. 2., No 1: 4

Hikmah, Dian Nurul. 2014. Prosesi dan makna simbolis topen dan sesaji dalam kesenian Cepetan di Dusun Condong Desa Condong Capur Kec. Serueng Kabupaten Kebumen. Universitas Negeri Yogyakarta. Fakltas Bahasa dan Seni.

Musdalifa, Andi. 2016. Nilai-nilai Budaya dalam Tiga Cerita Rakyat Tolaki (Pendekatan Sosiologi Sastra) Jurnal Humanika. No. 16., Vol. $1: 11$

Nur'Aini. dkk. 2013. Trdisi Upacara Nadran Pada Masyarakat Nelayan Cirebon di Keluruhan Kangkung Bandra Lampung. Jurnal Kebudayaan

Putra. 2010. Memahami Makna Simbol dalam Komunikasi dengan Dayak Jangkang. Jurnal Ilmu Komunikasi. Vol.7., No. 2:229

Ratna. 2015. Teori, Metode, dan Teknik Penelitian Sastra. Yogyakarta: Pustaka Pelajar 
Ratna. 2011. Antropologi Sastra Peranan Unsur-unsur Kebudayaan dalam Proses Kreatif. Yogyakarta: Pustaka Pelajar

Soehardi. 2002. Nilai-Nilai Tradisi Lisan dalam Budaya Jawa. Jurnal Humaniora. Vol. 14., No. 3:2

Suantoko. 2017. Makna Simbol Sastra Lisan Tanduk Masyarakat Adat Genaharjo Kabupaten Tuban. Jurnal Dilaektika. Vol.4., No. 1:42

Sudewa. 2014. Transformasi Sasttar Lisan ke dalam Seni Pertunjukan di Bali: Perspektif Pendidikan. Jurnal Humaniora. Vol. 26. No. 1:67

Sulistyorini dan Andalas. 2017. Sastra Lisan "Kajian Teori dan Penerapannya dalam Penelitian". Malng: Madani, Kelimpok Intras Publishing Wisma Kali metro.

Syamsurijal dan Musayyadah. 2014. Puisi Magis (Pangissengeng): Bentuk dan Makna (Magic Poetry Pangissengeng: Form and Meaning). Jurnal Saweri Gading. Vol.20 No.2:251-252

Teeuw. A. 2013. Sastra dan Ilmu Sastra. Bandung: PT. Dunia Pustaka Jaya :252

Wardani. S dan Soebijantoro. 2017. Upacara Adta Mantu Kucing di Desa Purworejo Kabupaten Pacitan (Makna Simbolis dan Potensinya sebagai Sumber Pembelajaran Sejarah). Jurnal Agastia. Vol.7., No. 1:66

Widianti, Nurhana, ddk. 2017. Tradsisi Pembacaan Babat Cirebon: Tinjauan Fungsi Willian. R. Basco. Jurnal Pendidikan Bahasa dan Sastra Indonesia. Vol 4. No. 2:177

Zekriady. 2008. Analisis Bentuk dan Makna Sastra Lisan Sumbawa Sakeco Suku Samawa di Kabupaten Sumbawa dengan pendekatan
Foklor. Jurnal Artikulasi. Vol. 6., No.2:295 
